\title{
A cobertura midiática dos crimes de violência contra a mulher :preconceito e silenciamentos
}

The media coverage of the crimes of violence against women : preconcept and silence

La cobertura midiática de los crímenes de violencia contra la mujer : preconceito y silencios

Couverture médiatique des crimes de la violence contre les femmes : préconcept et silence

\section{Katia Bélissario}

\section{OpenEdition}

\section{Journals}

Edição electrónica

URL: http://journals.openedition.org/ctd/2172

DOI: $10.4000 /$ ctd. 2172

ISSN: 2491-1437

Editora

Chaire Unesco Pratiques émergentes en technologies et communication pour le développement

Edição impressa

ISBN: 2491-1437

Refêrencia eletrónica

Katia Bélissario, «A cobertura midiática dos crimes de violência contra a mulher :preconceito e silenciamentos ", Communication, technologies et développement [En ligne], 7 | 2019, mis en ligne le 20 juin 2019, consulté le 06 juillet 2019. URL : http://journals.openedition.org/ctd/2172 ; DOI : 10.4000/ ctd. 2172

Este documento foi criado de forma automática no dia 6 Julho 2019.

Communication, technologies et développement 


\title{
A cobertura midiática dos crimes de violência contra a mulher :preconceito e silenciamentos
}

\author{
The media coverage of the crimes of violence against women : preconcept and \\ silence \\ La cobertura midiática de los crímenes de violencia contra la mujer : preconceito \\ $y$ silencios
}

Couverture médiatique des crimes de la violence contre les femmes : préconcept et silence

Katia Bélissario

\section{INTRODUÇÃO}

1 No Brasil, de acordo com o Anuário de Segurança Pública de 2017, ao todo são 49.497 estupros por ano, mais de 125 vítimas por dia. Estima-se que o número seja ainda maior : conforme aponta o Instituto de Pesquisa de Economia Aplicada (Ipea, 2011), apenas $10 \%$ dos casos são oficialmente registrados no país.

2 Até a década de 1980, a imprensa brasileira apresentava a vítima mulher como causadora de sua própria morte em casos de violência, principalmente doméstica. (BLAY, 2003, p 93). Embora esse tratamento de culpa atribuído à mulher não seja mais dessa forma na imprensa, ainda é preciso observar e pesquisar como a mulher é vista e abordada pelas notícias, além de como o agressor é apresentado.

Vale ressaltar que cabe à imprensa escolher reforçar o senso comum já enraizado ou desconstruí-lo com análises mais aprofundadas, dados atualizados e explicações além do óbvio. "A mídia participa de forma efetiva na construção de sujeitos e subjetividades, 
produzindo saberes e ensinando às pessoas modos de ser e estar na cultura" (FISCHER, 2002 apud SOUZA, T., OLIVEIRA, S., 2015, p. 4).“A mídia deve buscar fiscalizar diferentes interpretações da realidade e investigar ações que tenham condições de corrigir distorções sociais" (ANDI, GALVÃO,2011, p. 18).

É preciso que o conceito de estupro e estuprador sejam redefinidos socialmente. É necessário colocá-los de acordo com a realidade apresentada : "não possui cor, nem classe sócio-econômica e, principalmente, o estupro não precisa conter ingredientes extremos de violência para, por si só, ser considerado um ato brutal e ilegal" (COULOURIS, 2004, p 9).

5 As bases sócio-históricas devem ser levadas em consideração quando o assunto é violência sexual, principalmente quando as vítimas são meninas e mulheres. Esse tipo de violência na maioria das vezes diz respeito ao sentimento de dominação e posse que homens têm pelas mulheres. Sousa (2016, p 11) enfatiza que "é importante compreender que a realização do desejo sexual do agressor pode se manifestar de várias formas, mas nenhuma delas respeita a vontade e a dignidade da vítima".

6 Este trabalho parte da premissa de que o jornalismo tem a responsabilidade social de combater a violência e é a partir desta ótica que a pesquisa vai analisar a maneira como a imprensa noticia um caso emblemático de estupro coletivo e qual seu papel diante de um acontecimento desta dimensão. É pretendido não só analisar as notícias como também refletir sobre a responsabilidade que o jornalista tem de não só informar como também de ajudar na transformação social. Trata-se de uma pesquisa com o intuito de chamar atenção para a cultura de estupro e para a necessidade dos jornalistas de combatê-lo.

7 As perguntas de pesquisa que pretendemos responder aqui são: Por que a mídia tende a naturalizar os crimes de violência contra a mulher? Quais silêncios envolvidos? De que forma podemos trabalhar as questões de gênero com os futuros profissionais para evitar a misoginia?

\section{Metodologia e revisão teórica}

Neste artigo o procedimento metodológico utilizado é a Análise do Discurso da corrente francesa (AD). Essa abordagem propõe ir além do texto e seu objetivo principal é identificar, a partir de técnicas e conceitos específicos, os efeitos de sentido que o discurso produz a partir da relação entre texto e contexto (SCHWAAB, 2007). Ela sugere uma relação menos ingênua com a linguagem, a partir do pressuposto de que não há neutralidade nem transparência na língua.

9 Esse tipo de análise objetiva "procurar compreender o modo como um objeto simbólico produz sentidos não a partir de um mero gesto de decodificação, mas como um procedimento que desvende a historicidade contida na língua, em seus mecanismos imaginários" (ORLANDI, 2001, apud SCHWAAB, 2007, p. 16). 0 foco da análise do discurso não é propriamente o conteúdo do texto, mas sim os sentidos que ele produz. (CAREGNATO, MUTTI, 2006).

O jornalismo ocupa um espaço discursivo composto por interação, onde a materialidade, as vozes presentes (jornalista, fontes ouvidas e instituição), e o público andam juntos influenciando, incrementando ou contrapondo discursos anteriores ou paralelos (RINGOOT, 2006). A fonte que o jornalista escolhe para compor o discurso, por exemplo, já diz muito para a $\mathrm{AD}$, pois se trata de um espaço no discurso cedido para um outro sujeito 
que vai chegar para o leitor com uma dose de confiança fruto da permissão do jornalista (SCHWAAB, 2007).

11 Conforme explica Machado (2006), o jornalismo é capaz de produzir conhecimento como também de recriá-lo a partir das escolhas feitas na produção no discurso. Ele é uma construção social que depende e se submete a uma série de fatores e formatos com o intuito de retratar certos acontecimentos da realidade cotidiana. "A notícia é um dos eixos norteadores dos parâmetros sociais de normalidade e anormalidade" (MACHADO, 2006, p.5). Além disso, é a imprensa uma das responsáveis por causar e/ou propor reflexividade e se espera dela não apenas informar, como também orientar. (SCHWAAB, 2007)

O entendimento das notícias como construções sociais traz consigo a compreensão de que elas são narrativas marcadas pela cultura jornalística e pela cultura em geral. Assim, ao produzir a notícia, o jornalista estabelece uma série de relações (...). Para cumprir suas funções, ele se faz valer de técnicas, gêneros, formatos e processos de edição, por meio dos quais é possível escolher, excluir ou acentuar determinados aspectos dos acontecimentos (SCHWAAB, 2007, p. 12).

O jornalismo é responsável por incentivar e ajudar na formação de consensos, a partir da construção de sentido que ele dá para a realidade. (MACHADO, 2006) Mesmo que haja o objetivo de neutralidade e objetividade no texto jornalístico, a ideologia se faz presente, principalmente ao observar a relação do texto com o contexto. "O jornalista acredita ser detentor de um discurso isento e objetivo, quando na verdade carrega uma grande parcela de subjetividade em suas ações" (HAGEN, 2006, apud SCHWAAB, 2007).

Dessa forma, é papel do analista do discurso jornalístico desvendar o que se camufla nos formatos e técnicas da construção da notícia. É sua tarefa expor a opacidade do texto e mostrar os mecanismos que provocam esse efeito no discurso, mesmo quando são feitos de modo inconsciente (PÊCHEUX, 1981 apud ORLANDI, 2007). "No caso do discurso jornalístico, trata-se de analisar aquilo que conta o jornal, mas trata-se também de analisar como são posicionados os que o escrevem e os que o lêem, trabalhando sobre os dispositivos enunciativos, as formas de disponibilizar a informação" (RINGOOT, 2006, p. 135).

14 O intuito é desenvolver uma pequena análise do discurso das notícias destacadas para destacar os mecanismos que combatam ou reforcem a ideologia que gira em torno da desigualdade de homens e mulheres (patriarcal), presente na sociedade brasileira. Não é de pretensão da pesquisa esgotar o assunto ou adentrar em todas as possibilidades, mas apontar, a partir dessa tentativa inicial de análise do discurso, se e como o patriarcado se faz presente em noticiários que envolvem a violência de gênero e seus efeitos.

\section{Análise do discurso do portal g1}

O estupro coletivo que aconteceu no dia 25 de maio de 2016 no Morro do Barão, Rio de Janeiro, ganhou atenção nacional e internacional por uma série de fatores, sendo o primeiro deles a forma como o caso chegou até as autoridades - a partir de vídeos divulgados pelos próprios abusadores em redes sociais se vangloriando do ato de violência. Alguns outros pontos também chamaram, e ainda chamam atenção, como a quantidade de suspeitos envolvidos - inicialmente a hipótese era de 33 homens violentando uma adolescente de 14 anos desacordada - e também a comoção que isso causou e o debate que trouxe a tona quanto cultura de estupro. 
16 A seleção das notícias se deu em etapas : primeiro foi realizada uma busca no site do G1 com a combinação das palavras-chave : estupro coletivo ; Rio de Janeiro. A partir disso, foram selecionadas todas as notícias do período entre 25 de maio de 2016, quando saiu a primeira notícia, e 17 de junho de 2016, data da conclusão do inquérito policial. Ao todo, foram selecionadas 103 notícias na etapa de recorte, divididas em quatro blocos: 1) Notícias que falam sobre o caso e o desenrolar dos acontecimentos - a denúncia do estupro, o indiciamento de suspeitos, a troca de delegado e laudo médico. 2) Ações governamentais de combate à violência contra a mulher motivadas pelo caso pronunciamento de instituições nacionais e internacionais abordando a gravidade do acontecimento e repudiando a violência de gênero. 3) Informações adicionais para a contextualização do assunto - informações sobre cultura de estupro, lei do estupro, mecanismos de combate à violência que já existem etc. 4) Notícias sobre as manifestações que aconteceram em todo país após a repercussão do caso.

17 As informações adicionais para contextualizar o assunto representam pouco mais de $5 \%$ do total das selecionadas. Deste número, nenhuma traz conteúdo específico sobre mecanismos de denúncias e recursos existentes para acolhimento da jovem vulnerável, ou sobre culpabilização da vítima. A quantidade de notícias sobre mobilizações populares que aconteceram após a divulgação do caso foi $25,75 \%$, um total de 25 notícias. Todas articuladas por grupos de mulheres.

18 Para aplicar a Análise do Discurso, foi feita uma segunda seleção com 10 notícias que mostrassem aspectos-chave do que foi noticiado. Para o presente trabalho foram escolhidas três dessas notícias para a análise (TABELA 1). A seleção se deu a partir da seleção de pontos chave da investigação do caso e que ganharam grande repercussão nacional.

Quadro 1 - Corpus da Análise

\begin{tabular}{|l|l|l|l|}
\hline & Título & Data & Motivo de seleção \\
\hline 01 & $\begin{array}{l}\text { Vítima de estupro coletivo no } \\
\text { Rio conta que acordou dopada } \\
\text { e nua }\end{array}$ & $26 / 05 / 2016$ & $\begin{array}{l}\text { Primeiras informações sobre a vítima do } \\
\text { estupro coletivo. }\end{array}$ \\
\hline 02 & $\begin{array}{l}\text { 'Errada era ela', diz suspeito } \\
\text { de estupro coletivo no Rio }\end{array}$ & $06 / 06 / 2016$ & $\begin{array}{l}\text { Primeira notícia sobre a declaração de um dos } \\
\text { suspeitos. }\end{array}$ \\
\hline 03 & $\begin{array}{l}\text { Polícia investiga quantas } \\
\text { pessoas levaram menina para } \\
\text { abatedouro' }\end{array}$ & $09 / 06 / 2016$ & $\begin{array}{l}\text { Notícia que aponta número de participantes do } \\
\text { estupro coletivo, importante para } \\
\text { entendimento do desfecho do caso. }\end{array}$ \\
\hline
\end{tabular}

Fonte : Feito pelas Autoras do Artigo

20 Como a análise de discurso (AD) é uma metodologia muito complexa, foram definidos quatro pontos de observação : os sujeitos ; os silêncios ; as aspas ; e outros elementos que compõem a narrativa como imagem, participação do leitor etc. Para facilitar o entendimento, apresentamos a seguir um resumo da notícia, com o link a ser acessado e a análise das categorias. 


\section{Análise das notícias}

\section{Pronunciamento da vítima}

\section{A notícia}

21 Essa é a segunda notícia presente no portal sobre o caso. Enquanto a primeira não traz informações sobre quem eram os envolvidos, número de pessoas, identificação da vítima ou sequer enfoque na violência sexual, esta segunda já mostra os avanços das investigações e também o posicionamento da vítima que é ouvida pela justiça. ${ }^{1}$

O primeiro aspecto do texto jornalístico, o lide, resume a declaração da vítima à Delegacia de Repressão de Crimes de Informática (DRCI). Cabe entender o contexto dessa notícia : um depoimento que não era destinado à imprensa, feito por uma vítima menor de idade de um estupro coletivo que envolvia mais de 30 homens. Cabe considerar a exposição que a mídia deu ao depoimento os pontos enfatizados, principalmente pelas condições que a vítima se encontrava.

\section{Os sujeitos}

23 No texto, são identificadas sete vozes: a vítima; a avó da vítima; a Delegacia de Repressão aos Crimes de Informática; o delegado responsável pelo caso ; o Ministério Público do Rio de Janeiro, a Comissão de Direitos Humanos da Câmara Municipal do RJ e a OAB-RJ, por meio da comissão permanente OAB Mulher.

O discurso é polifônico, embora haja grande desigualdade no espaço dado a cada um. As vozes da vítima e da avó são ouvidas primeiro, já que são as responsáveis pela formação do sentido central da notícia. Em seguida, vem as fontes oficiais, deixando para o final da matéria, depois das informações repetidas da primeira notícia, as notas de repúdio ao estupro divulgadas pelas instituições como: OAB Mulher e Comissão de Direitos Humanos.

\section{C) Os silêncios}

O sentido principal do texto é o depoimento da vítima na delegacia. No segundo parágrafo aparece a seleção de alguns trechos do relato para conduzir a notícia. A primeira informação trazida é que ela foi para a casa de um rapaz com quem se relacionava há três anos e depois, sem lembrar-se de muita coisa, acordou no dia seguinte, sem roupa e em outra casa. Nada é falado sobre o rapaz, se ele vai ser investigado e o fato dela não se lembrar de nada. É descrito estado da vítima : "dopada e nua”, colocado como o título da matéria, sem preocupação com a sua exposição, já que a descrição feita foi para o delegado e não à imprensa.

Outro silenciamento identificado diz respeito ao destaque da informação de que a vítima voltou ao local do crime no dia seguinte ao estupro para recuperar o celular roubado. Esse fato mostra a maneira como o estupro é abafado e naturalizado - denunciar não era uma opção para a vítima. Não há qualquer explicação sobre as dificuldades em denunciar, ou a importância de procurar um médico. Ao focar no fato da vítima ir buscar o celular, deixase a impressão que a violência é algo corriqueiro. Perde-se a oportunidade de trazer à tona fatores socialmente relevantes sem apelar para desmoralizá-la. 
27 Há silêncios quanto à urgência de a vítima ser encaminhada a exames de corpo de delito do IML e receber auxílio médico, decorridos quatro dias da violência. Também nada foi falado sobre os perigos e problemas que o estupro acarreta.

\section{D) As aspas}

Nos últimos parágrafos do texto aparecem duas notas de repúdio ao caso, trazendo à tona a gravidade da violência. Trechos das notas são colocados entre aspas, ao invés de descritos - como foi feito em todas as outras declarações da matéria -, o que deixa a responsabilidade do conteúdo para as instituições responsáveis pela nota.

\section{E) Outros elementos}

29 A inversão da estrutura "ela admitiu que faz uso de drogas, mas afirmou que não utilizou nenhum entorpecente no sábado" mostra o mecanismo ideológico dominante de buscar desviar a atenção da violência para outros fatores que instigam o leitor a culpá-la pelo estupro, reforçando a a ideia de que a vítima tem um perfil específico.

É uma forma de dar menos credibilidade à existência da violência e de questionar o relato da vítima. No relato da avó da vítima é possível perceber o efeito de seleção e o mecanismo presente de desmoralização da jovem, com informações que a expõe e que em nada interferem na notícia. A descrição do vídeo como "chocante" é o ponto central da fala da avó, colocada entre aspas para dar uma voz mais ativa e direta a ela. Em seguida, reforçam o uso de drogas por parte da vítima e acrescentam que ela tinha o hábito de ir à comunidade desde os 13 anos e que é mãe.

31 Ao resgatar o texto da primeira notícia sobre a investigação feita pelo Ministério Público do Rio de Janeiro, o questionamento sobre o estupro é mantido : “o MPRJ informou que está investigando o caso da jovem que aparece desacordada em um vídeo após supostamente ter sido estuprada" O objetivo é informar o leitor que não leu a primeira notícia e quer saber como a investigação do caso começou, reforçando a dúvida do Ministério Público quanto à existência do estupro. 0 discurso questiona o comportamento da vítima, sem a preocupação em combater a violência contra a mulher e a cultura do estupro.

\section{Primeira Declaração de um dos Suspeitos}

\section{A) A notícia}

32 Durante o intervalo de tempo entre a segunda notícia selecionada e essa, houve mais suspeitos identificados e o caso ganhou visibilidade nacional, com manifestações em todo o país. o foco central desta notícia está no subtítulo e no lide : o depoimento, ao qual a imprensa teve acesso, de um dos suspeitos presos, que tinha um celular com novas gravações e provas do crime. ${ }^{2}$

\section{B) Os sujeitos}

O principal sujeito da notícia é um dos envolvidos no estupro coletivo, que admite a relação sexual com a jovem, mas nega o estupro. Ao contrário, ele justifica a ação porque a vítima estava no lugar errado ("nem era o lugar dela"). 
34 Há mais um sujeito falante : a delegada do caso, que aparece nas últimas linhas do texto e não é apresentada como delegada. Há outras fontes que participam : agentes da delegacia e policiais. O discurso, monofônico, destaca o suspeito e traz informações complementares apontadas em outras notícias, como o aparecimento do celular com novas gravações, a prisão de dois suspeitos e a busca por outros cinco.

\section{C) Os silêncios}

Os silêncios estão por toda parte : faltam fontes para contrastar a declaração polêmica do suspeito e faltam novidades para justificar a existência da notícia, já que o único fato novo apresentado são os trechos da declaração do suspeito. Enfatizar esses trechos, e não trazer nenhuma reflexão complementar, é uma forma de manter a cultura do estupro e se ausentar do problema; é concordar e apoiar a ideologia dominante no discurso do suspeito.

\section{D) As aspas}

As aspas no título referem-se ao trecho mais polêmico do depoimento do suspeito: "Errada era ela". No lide, esse trecho é descrito pelo jornalista : “...afirmou que a vítima estava "errada" por estar na comunidade onde sofreu abusos sexuais". No segundo parágrafo, o trecho é novamente destacado com outra citação direta contendo a mesma frase do título, descrita no lide: "ali era lugar dos traficantes, nem era o lugar dela. Errada era ela de estar ali, Deus me livre". No décimo parágrafo, a informação é novamente trazida à tona, mas dessa vez mostrando que ele estava articulando uma manifestação na comunidade para negar o estupro. São quatro trechos com o mesmo sentido na argumentação e enfoque, sendo que os três primeiros ocupam posições nobres do texto jornalístico. Essa repetição é um discurso que enfatiza a informação escolhida para culpar a vítima.

\section{Investigação sobre a quantidade de envolvidos no crime}

\section{A) A notícia}

37 Em 09 de junho de 2016 a notícia trata da investigação policial sobre quantos homens abusaram sexualmente da vítima. É um apanhado do caso com as últimas informações da investigação - quem está preso, quantos estão foragidos e novos depoimentos - e da situação da vítima, que teve que sair do Rio de Janeiro, devido ao número de ameaças recebidas por ter denunciado o estupro. É explicado o motivo pelo qual a polícia estava refazendo o trajeto até o local do crime : foi verificado, em investigações anteriores, que uma pessoa só não seria capaz de levar a vítima até o local do abuso, já que ela estava desacordada. ${ }^{3}$

\section{B) Os sujeitos}

38 O discurso tem três sujeitos falantes : a delegada do caso, um suspeito que foi solto por falta de prova, e o pai dele. Esta é a primeira notícia da análise em que o sujeito central é a delegada que investiga o caso, um enfoque real na investigação. 


\section{C) Os silêncios}

Fala-se em muitos suspeitos e é feito um "rescaldo" do que foi publicado em quase um mês de cobertura do caso. Não há dados sobre estupros, condições de denúncias, ou formas de denunciar. A notícia foca na investigação sobre o número de suspeitos, mas silencia sobre a polícia descartar um número maior de suspeitos, mesmo com os áudios apontando a participação deles. Pouco se fala sobre o número de envolvidos aumentar à medida que a investigação se aprofunda.

\section{D) As aspas}

40 A colocação do termo "abatedouro" no título mostra tratar-se de uma expressão que não é do veículo. Embora não seja dito diretamente, o termo é a expressão que o veículo usa para se referir ao local do crime. Chamar o lugar onde uma adolescente foi violentada por vários homens de "abatedouro"- em linguagem vulgar, lugar onde homens solteiros se encontram livremente para o sexo com mulheres disponíveis - é tirar o peso da violência e dar voz à naturalização do que era praticado lá.

O termo é repetido duas vezes. Na primeira, é explicado que o local era conhecido assim e na segunda, entre colchetes, dentro das aspas da delegada do caso, afirma-se que refizeram o trajeto de uma casa a outra. A escolha por reproduzir e repetir o termo faz com que o local faça parte do imaginário do público leitor. De maneira indireta, a palavra carrega a ideia de que aquele foi o lugar onde levaram a vítima para o "abatimento" e "consumo" de suas carnes (públicas).

42 Nas aspas da delegada responsável pelo caso é enfatizado que o jogador de futebol, suspeito de participar do crime, não está fora da investigação, embora não tenham provas contra ele. Nas aspas do pai do jogador ele afirma não ter com o que se preocupar, contrastando com o que foi dito pela delegada no parágrafo anterior. A delegada afirma que a punição dos suspeitos deve ser exemplar. $O$ uso de aspas por parte da delegada aparece três vezes ao longo do texto.

\section{E) Outros elementos}

Essa é a primeira notícia assinada, talvez devido à repercussão do caso, com visibilidade nacional e internacional. A responsabilidade, que antes recaía sobre o veículo, agora é dividida com a autoria do jornalista.

\section{0 caso do new york times}

Em 2007, uma pesquisa conduzida pelo Campus Sexual Assault Study (CSA), criado pelo Instituto Nacional de Justiça dos Estados Unidos, publicou que 1 em cada 5 jovens universitárias sofreram estupros, ou tentativas de assédio sexual desde que entraram na universidade. Quando o foco foi com mulheres mais velhas, o número registrado foi que 1 entre 4 universitárias foram vítimas de estupros tentativas de assédio.

Apesar dos Estados Unidos ser um país desenvolvido, o silenciamento e a culpabilização das vítimas na mídia pode ser comparado ao que ocorre na mídia brasileira. Em março de 2011, por exemplo, o conceituado jornal The New York Times publicou a estória de um estupro coletivo de uma colegial na cidade de Cleveland, no estado do Texas. Bloggers, 
jornalistas, e demais leitores, logo identificaram aspectos patriarcais e de culpabilização da vítima na cobertura jornalística. Foram colhidas 50.000 assinaturas em um abaixoassinado pedindo uma retratação do jornal, o que resultou em um pedido de desculpas formal do The Times. 0 jornal esclareceu que não era a intenção do repórter culpar a vítima e que ele somente mostrou os comentários da comunidade.

Durham (2013) publicou um artigo na revista Journalism Studies Volume 14, $n^{\circ} 1,2013$, onde faz uma análise crítica textual da cobertura do The Times pelo repórter McKinley. A análise crítica consiste em "uma recíproca relação entre uma retórica e uma ideologia" (ECO,1967, tradução nossa). Para a autora do artigo, a análise textual é particularmente útil na conexão entre ideologia e técnicas narrativas.

47 A análise da pesquisadora revela, como a que fizemos no portal $\mathrm{G} 1$, a abordagem misógina do repórter James McKinley do jornal, com o uso de aspas e estruturas léxicas estratégicas no texto para culpabilizar a vítima por suas vestimentas e comportamento e enfim, naturalizar os acontecimentos. Observemos, por exemplo esse trecho: "Eles disseram que ela se vestia como uma mulher mais velha, usando maquiagem e roupa da moda mais apropriada para uma mulher de 20 anos. Ela ficava agarrada com meninos adolescentes em um playground, alguns disseram' (McKinley, 2011, para. 12).

Os responsáveis pelo estupro, por outro lado, são dignos de pena, como está escrito nesse trecho : "Esses garotos terão que viver com isso para o resto das suas vidas" (McKinley, 2011, para. 5). E o que dizer da colegial ; ela por acaso não terá que viver com esta amarga realidade no seu dia a dia ? Nada é falado sobre a vida da vítima.

Observamos, portanto, como são bastante semelhantes as formas de abordar casos de violência contra a mulher em todos os países. Uma visão patriarcal, misógina, preconceituosa e que naturaliza os fatos.

Vejamos a seguir o quadro comparativo da abordagem do G1 e do New York:

Quadro 2 - Quadro Comparativo G1 e The New York Times

\begin{tabular}{|l|l|l|l|l|l|}
\hline Mídias & $\begin{array}{l}\text { Uso de } \\
\text { Aspas pelo } \\
\text { Jornalista }\end{array}$ & $\begin{array}{l}\text { Culpabilização } \\
\text { da Vítima }\end{array}$ & $\begin{array}{l}\text { Justificativa : } \\
\text { Trajes usados pela } \\
\text { vítima } \\
\text { comportamento }\end{array}$ & $\begin{array}{l}\text { Silenciamento } \\
\text { Da Vítima }\end{array}$ & $\begin{array}{l}\text { Empatia com } \\
\text { os } \\
\text { agressores }\end{array}$ \\
\hline $\begin{array}{l}\text { Portal } \\
\text { G1 }\end{array}$ & $\mathrm{x}$ & $\mathrm{x}$ & $\mathrm{x}$ & $\mathrm{x}$ & $\mathrm{x}$ \\
\hline $\begin{array}{l}\text { The New } \\
\text { York } \\
\text { Times }\end{array}$ & $\mathrm{x}$ & $\mathrm{x}$ & $\mathrm{x}$ & $\mathrm{x}$ & $\mathrm{x}$ \\
\hline
\end{tabular}

Fonte : Feito pelas Autoras do Artigo

51 Como se pode observar as abordagens se repetem tanto na mídia brasileira selecionada quanto no jornal de referência norte-americano. Uma demonstração de que os padrões patriarcais de tratamento às mulheres se repetem em ambos países. 


\section{Considerações finais}

52 Este artigo mostra que os crimes de violência contra mulheres e meninas são abordados praticamente da mesma maneira, sejam eles cometidos em países desenvolvidos, como os Estados Unidos, ou em desenvolvimento, como o Brasil. Usando a metodologia da Análise do Discurso francesa (AD), analisamos a cobertura jornalística pelo portal G1 de um estupro coletivo de uma jovem de 16 anos, ocorrido no Rio de Janeiro, em 2016. Depois, comparamos essa abordagem com a polêmica cobertura do New York Times de um estupro coletivo de uma colegial, ocorrido no estado do Texas, Estados Unidos, em 2011

Observamos que há, em ambas as mídias, uma tendência à naturalização da violência contra a vítima e à injusta culpabilização das duas jovens pelo estupro sofrido por elas. De modo geral, insinua-se e justifica-se que o crime ocorreu devido às roupas sensuais usadas, à maquiagem exuberante, ao comportamento insinuante, ao uso de drogas, às preferências musicais e à uma intensa vida sexual, apesar de ainda jovens.

54 As perguntas que nos propomos a responder com esta pesquisa foram : Por que a mídia tende a naturalizar os crimes de violência contra a mulher? Quais silêncios envolvidos? A análise feita demonstra um padrão patriarcal e misógino em ambos os países que determina o lugar de estar e de fala de uma mulher, ou menina. Conforme ressalta a pesquisadora brasileira Heleith Saffioti (2004), há na sociedade uma naturalização da violência, uma tolerância e até mesmo, um incentivo para que os homens exerçam a masculinidade de modo agressor.

Assim sendo, sugere-se que para ser respeitada e não se tornar vulnerável ao estupro, as mulheres, e meninas adolescentes devem estar em ambientes domésticos, em lugares ditos "de respeito", serem recatadas, não frequentarem determinadas festas e eventos, não usarem drogas, usarem roupas pouco insinuantes, pouca maquiagem, ter escolhas musicais tradicionais, poucos ou mesmo, nenhum relacionamentos sexuais e enfim, se fecharem para o mundo externo. Observamos ainda, que quando ocorre a violência não há espaço de fala para a vítima, que é desrespeitada e questionada por todos (comunidade, delegados, policiais, repórteres) e em todos os sentidos. Só o agressor tem vez e voz; o silêncio impera para a vítima.

Indagamos de que forma poderíamos trabalhar as questões de gênero com os futuros profissionais nas escolas de comunicação, de forma a evitar a misoginia. É imprescindível um treinamento em comunicação e questões de gênero nas universidades para que futuros jornalistas sejam mais conscientes do importante papel que desempenham na agenda da sociedade e de sua responsabilidade social na construção da notícia. É necessário enfim, que jovens jornalistas compreendam que "a notícia é um dos eixos norteadores dos parâmetros sociais de normalidade e anormalidade" (MACHADO, 2006, p. 5).

57 Certamente os questionamentos não se esgotam com nessas constatações, mas a intenção do presente artigo é abrir espaço para o aprofundamento do debate e para esforços conjuntos no sentido de buscar caminhos para combater o preconceito e os silenciamentos da mídia no mundo. 


\section{BIBLIOGRAFIA}

\section{Referências bibliográficas}

ANDI - COMUNICAÇÃO E DIREITOS, INSTITUTO PATRÍCIA GALVÃO. Violência contra a mulher : estudo revela predominância de viés policialesco na cobertura noticiosa do tema. Brasília. 2011, http://www.andi.org.br/sites/default/files/resumo_executivo_mulher_violencia_ANDI_2011.pdf , Acesso em : 27 de janeiro de 2017.

BLAY, E. Violência contra a mulher e políticas públicas. In : Estudos avançados no 17. Universidade de São Paulo. 2003. http://www.scielo.br/scielo.php? script=sci_arttext\&pid=S0103-40142003000300006. Acesso em 02 de fevereiro de 2017.

CAREGNATO, Rita ; MUTTI, Regina. Pesquisa qualitativa : análise de discurso versus análise de conteúdo. Texto contexto, Porto alegre, v. 4, n. 1, p. 679-684, out. 2006. Disponível em : http:// www.scielo.br/pdf/tce/v15n4/v15n4a17 Acesso em : 15 de maio de 2017.

COULOURIS, D. Violência, gênero e impunidade : a construção da verdade nos casos de estupro. In XVII Encontro Regional de História - O lugar da história. Universidade de Campinas. São Paulo. Setembro de 2004. https://www.anpuhsp.org.br/sp/downloads/CD\%20XVII/ST\%20VII/Daniella\% 20Georges\%20Coulouris.pdf. Acesso em : 17 de março de 2017.

DURHAM, Meenakshi Gigi. "Vicious Assault Shakes Texas Town": The Politics of Gender Violence in the New York Times' Coverage of a Schoolgirl'S Gang Rape. In :Journalism Studies. Vol 14, $\mathrm{n}^{01} 1,2013$. Acesso em 30 de outubro de 2017.

ECO, Umberto. Rethoric and Ideology in Eugene Sue's 'Les Mystéres de Paris'. International Social Science Journal 19 (4), 1967, p. 48-78.,

MACHADO, Márcia. Jornalismo e perspectivas de enunciação : uma abordagem metodológica. Intertexto, Porto alegre, v. 1, n. 14, p. 1-11, jan. 2006. Disponível em : <http://seer.ufrgs.br/ index.php/intexto/article/view/4251>. Acesso em : 18 de maio de 2017.

MCKINLEY, JAMES C. “Vicious Assault Shakes Texas Town”, The New York Times, 8 March, 2011,p. 13A.

ORLANDI, Eni. Análise de discurso : princípios e procedimentos. 7 ed. São Paulo : Pontes, 2007. $99 \mathrm{p}$.

RINGOOT, Roselyne. Por que e como analisar o discurso no contexto dos estudos sobre jornalismo. Comunicação e espaço público, Brasília, v. 2, n. 1, p. 133-139, jan. 2006.

SAFIOTTI, Heleieth. Gênero Patriarcado e Violência. São Paulo : Perseu Abramo, 2015.

SCHWAAB, Reges. Para ler de perto o jornalismo : uma abordagem por meio de dispositivos da análise do discurso. Em questão, Porto alegre, v. 13, n. 1, p. 11-23, jan. 2007. Disponível em : http://seer.ufrgs.br/index.php/EmQuestao/article/view/2002 Acesso em :03 de maio de 2017. SOUSA, R. Cultura do estupro : prática e incitação à violência sexual contra mulheres. In Revista Estudos Feministas. Universidade Federal de Santa Catarina. Florianópolis. Janeiro de 2016. https://periodicos.ufsc.br/index.php/ref/article/view/48512 Acesso em : 19 de março de 2017. 
SOUZA, T., OLIVEIRA, S. Violência contra a mulher na imprensa : o caso do jornal "o popular". Universidade do Estado da Bahia. Bahia. Julho de 2015. http://www.uneb.br/ enlacandosexualidades/files/2015/07/Texto-completo-Violencia-Contra-a-Mulher-naImprensa.pdf> Acesso em : 05 de março de 2017.

\section{NOTAS}

1. Vítima de estupro coletivo no Rio conta que acordou dopada e nua. Disponível em :http:// g1.globo.com/rio-de-janeiro/noticia/2016/05/vitima-de-estupro-coletivo-no-rio-conta-queacordou-dopada-e-nua.html. Acesso em : 31 de julho de 2017.

2. Errada era ela', diz suspeito de estupro coletivo no Rio. Disponível em : http://g1.globo.com/ rio-de-janeiro/noticia/2016/06/ali-era-o-lugar-dos-traficantes-diz-suspeito-de-estupro-coletivono-rio.html. Acesso em : 31 de julho de 2017.

3. Polícia investiga quantas pessoas levaram menina para 'abatedouro'. Disponível em : http:// g1.globo.com/rio-de-janeiro/noticia/2016/06/policia-investiga-quantas-pessoas-levarammenina-para-abatedouro.html. Acesso em : 31 de julho de 2017.

\section{RESUMOS}

De modo geral, jornalistas no Brasil, e também em outras partes do mundo, mostram uma tendência à naturalização dos crimes de violência contra a mulher. Este artigo pretende mostrar exemplos de como essa naturalização ocorre a partir de reportagens que tratam do crime de um estupro coletivo de uma jovem de 16 anos, ocorrido no Rio de Janeiro em 2016, publicado no portal G1 do Brasil. Também mostramos a cobertura misógina do New York Times sobre um estupro coletivo ocorrido no Texas em 2012. As perguntas de pesquisa que buscamos responder são : Por que a mídia tende a naturalizar os crimes de violência contra a mulher? Quais silêncios envolvidos? De que forma podemos trabalhar as questões de gênero com os futuros profissionais para evitar a misoginia? A metodologia utilizada é a análise do discurso das reportagens do portal G1, comparadas à cobertura do New York Times.

In general, journalists in Brazil, as well as in other parts of the world, show a trend towards the naturalization of crimes violence against women. This article intends to show examples of how this naturalization occurs from reports that deal with the crime of a gang rape of a 16 year old woman, occurred in Rio de Janeiro in 2016, published in the portal G1 of Brazil. We also show the New York Times misogynist coverage of a gang rape that occurred in Texas in 2012. The research questions we seek to answer are: Why does the media tend to naturalize crimes of violence against women? What are the silences involved? How can we work on gender issues with future professionals to avoid misogyny? The methodology used is the discourse analysis of the G1 portals, compared to the coverage of the New York Times.

En general, periodistas en Brasil, y también en otras partes del mundo, muestran una tendencia a la naturalización de los crímenes de violencia contra la mujer. Este artículo pretende mostrar ejemplos de cómo esa naturalización ocurre a partir de reportajes que tratan del crimen de una violación colectiva de una joven de 16 años, ocurrida en Río de Janeiro en 2016, publicada en el 
portal G1 de Brasil. También mostramos la cobertura misógina del New York Times sobre una violación colectiva ocurrida en Texas en 2012. Las preguntas de investigación que buscamos responder son : ¿Por qué los medios tienden a naturalizar los crímenes de violencia contra la mujer? ¿Cuáles silencios involucrados? ¿De qué forma pueden trabajar las cuestiones de género con los futuros profesionales para evitar la misoginia ? La metodología utilizada es el análisis del discurso de los reportajes del portal G1, comparados a la cobertura del New York Times.

En général, les journalistes au Brésil, ainsi que dans d'autres parties du monde, montrent une tendance à la naturalisation des crimes de violence à l'égard des femmes. Cet article a pour but de montrer comment cette naturalisation se produit à partir de reportages traitant du crime de viol collectif commis contre une femme de 16 ans à Rio de Janeiro en 2016, publiés sur le portail G1 du Brésil. Nous montrons également la couverture misogyne du New York Times sur un viol collectif au Texas en 2012. Les questions de recherche auxquelles nous cherchons à répondre sont les suivantes : pourquoi les médias ont-ils tendance à naturaliser les crimes de violence à l'égard des femmes? Quels sont les silences impliqués? Comment pouvons-nous travailler les questions de genre avec les futurs professionnels pour éviter la misogynie? La méthodologie utilisée est l'analyse du discours des portails G1, comparée à la couverture effectuée par le journal New York Times.

\section{ÍNDICE}

Mots-clés: Couverture journalistique, violence contre les femmes, misogynie, silence, éducation. Palavras-chave: Cobertura jornalística, violência contra a mulher, misoginia, silêncios, educação.

Palabras claves: Cobertura periodística, violencia contra la mujer, misoginia, silencios, educación.

Keywords: Journalistic coverage ; violence against women ; misogyny ; silence, education.

\section{AUTOR}

\section{KATIA BÉLISSARIO}

Université de Brazilia, Brésil 